\title{
The effect of Azadirachta Indica extract on the soil nutrients and the NPK value determination by electrochemical sensor
}

\begin{abstract}
Background: This paper focuses on the analysis of the contents of macro nutrients present in soil and the effect of Azadirachta indica extract on soil macro nutrients. Soil nutrient plays a vital role in the growth of crops and Azadirachta Indica extract being an organic matter, eco friendly and readily available in nature is also an excellent fertilizer. The amount of nutrients available from the soil (both micro and macro) other than those obtained from atmosphere through photosynthesis (hydrogen, carbon and oxygen) to the roots of the plant is the main factor which limits the yield of crops. There is a constant need of fertilizer which is bio-degradable, environment friendly and maintains soil fertility for a longer period of time or can at least last throughout the year. Sensing of these parameters is essential as they are used to monitor the impact of past, present and future fertility practices and on changes in a field's nutrient status. Sensing of macro nutrient (nitrogen, phosphorous and potassium) is possible with the electrochemical sensors. Azadirachta indica tree has engaged a worldwide attention owing to its variety of medical properties, antibacterial, anti-inflammatory, antioxidant. Here, its extract in soil acts as a fertilizer that reduces the run-off of Nitrogen, and enriches the amount of nutrients and organic matter and thus it heavily reduces the necessity of synthetic fertilizers. Azadirachta indica extract together with the soil can also be considered as Nitrogenous Organic Fertilizer. We can use it especially on the soils that are poor in organic matter or where intensive crops are cultivated like vegetables and fruits.
\end{abstract}

Keywords: NPK soil nutrient, Azadirachta indica extract, organic matter, electrochemical sensor
Volume 5 Issue 3 - 2019

\author{
Nameesha Chauhan, Shabana Urooj \\ Department of Electrical Engineering, Gautam Buddha \\ University, India
}

\begin{abstract}
Correspondence: Nameesha Chauhan, Department of Electrical Engineering, Gautam Buddha University, Greater Noida, Gautam Buddh Nagar, India,
\end{abstract} Email nameeshagbul7@mail.com

Received: April 30, 2019| Published: May 17, 2019

\section{Introduction}

The soil macro nutrients (nitrogen, phosphorous \& potassium) are necessary components for good healthy crops. The utilization of monetary NPK fertilizers has subsidized to excellent and exceptional increase in production of crops which provide food for the population. Nowadays immoderate use of the fertilizers has done corrosion of both land and ground water. The operation rates must be modified by building upon estimation of the necessities. Fettle soil configures the base of the ecology everywhere which intern leads to the production of healthy crops. Maintaining soil fertility requires a lot of management, caution, awareness and vigilance from farmers. Recently, degradation in total productivity and growth rates of major crop is realized due to declining in the efficiency of nutrient leading to fall in soil fertility. ${ }^{1}$ Factors for the declining of soil may include nutrient demand, declining in organic matter contents, excessive use of synthetic imbalanced fertilizers over a long period of time which leads to high nutrient turnover in soil- plant system, emerging deficiencies of secondary micro nutrients, nutrient leaching, removal of fertile top layer of soil due to flooding, fixation problems, soil pollution and acidity, other mineral deficiencies etc. ${ }^{1}$ Thus, to enhance and ensure production of crops a real time tests for the detection of soil nutrients is needed so that prevention of degradation of soil can be achieved. Here, we have given a detailed report on the use of wireless based sensor technology to establish a require scale of soil nutrients. A consequent amount of energy is wasted in the excessive employment of fertilizers, chemicals waste which can be reduced by the use of organic matter up to a minimum amount by $70 \%{ }^{1}$ The extended use of this sensor technology can be globally used in farming for the far-flung productivity of crops and observe and detect the materialistic state as well as the chemical state of the soil. Numerous sensors are known which performs distinct tasks in soil like chemical monitoring, moisture monitoring and monitoring of water quality etc. This technology here senses the soil macro nutrient composition in real time and a timely observation is kept on the soil as per the measured deficit or excess chemical condition, by applying the suitable organic fertilizer compost. Azadirachta indica tree is native to India and is easily available. It is biodegradable thus, a great deal of is added with other fertilizers. Thus, enhancing productivity of soil as it encourages nitrification. Since, this compound is free of heavy metals thus it protecting agricultural crops and best for soil use and also its decomposition prevents the development of pathogenic fungi. It decomposes in soil homogenously and slowly which leads to the nutrient consumption by soil in steady and uniform manner which establish the persistent growth of crops growing during a season. Azadirachta indica extracts are most cost efficient as the nutrient value in its lasts longer. It can also be available in the form of powder, granules or pellets. The Azadirachta indica extracts helps the soil to effectively maintain the soil nutrient level before the next season comes for crop plantation as it is sustainable organic matter in long run. The soil amendment is always two-fold. It helps to yield a better crop as it serves the nutrients as per the crop requirement. Also, it reduces the nematodes and growth of other harmful plant pathogens thereby diminishing crop diseases. The Azadirachta indica extracts 
increases the water holding capability of the soil along with the improvement in the structure of soil as well as keeps the soil aerated for root development. Azadirachta indica is appropriate for soil microbes as it will boost the rhizospheric flora that enhances the soil health. Azadirachta indica also fixes the soil texture. It can be used in both in open fields and localized. Azadirachta indica extract is a complete natural product and does not contain any solvents and other harmful components.

\section{System design}

Here, we have established an electronic system for the determination of soil macro nutrients. The technique is based upon Flow Injection Analysis (FIA) in which two electrodes work as 'flowthrough' in the electrochemical sensor for the recognition of nutrients. The system comprises of following components (Figure 1).

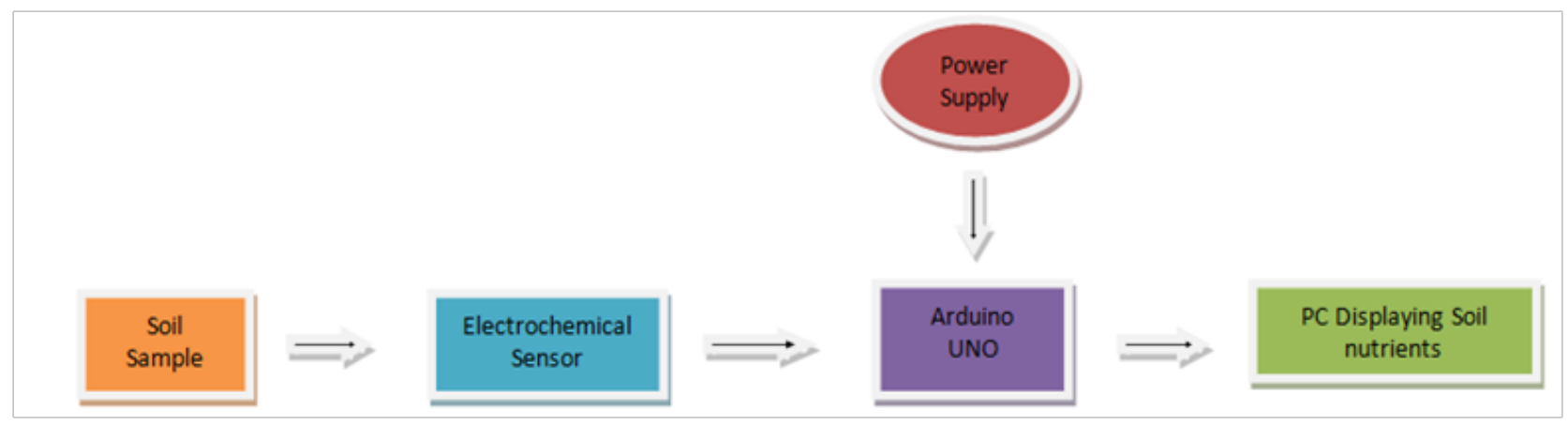

Figure I Block Diagram of sensor circuit.

\section{Block diagram description}

\section{Electrochemical sensor}

The electrochemical sensor gives information about the real time system that reciprocate to ion which are targeted thus transforming the chemical reactions to significant electrical signals by coupling chemical reaction. It consists of two electrodes-sensing electrode and counter electrode. ISE (Ion Selective Electrode) and ISFET (Ion Selective Field-Effect Transistor) are generally used as electrochemical sensor for soil nutrient detection. Due to time delay in sensing in ISEs it is not suitable whereas ISFET have a diffusion barrier. In case of environment free of chemical reactions, oxygen is diffused in the cell and get adsorbs on both the electrodes which results in a stable potential difference between both the electrodes where little current flows through it. The capillary comes in contact with the cathode when $\mathrm{O}_{2}$ enters in the sensor and is straight away gets reduce to $\left[\mathrm{OH}^{-}\right]$ions. It is cheaper in cost too. Figure 2 shows the ion selective field effective transistor (ISFET) electrochemical sensor ${ }^{2}$ and circuit diagram.

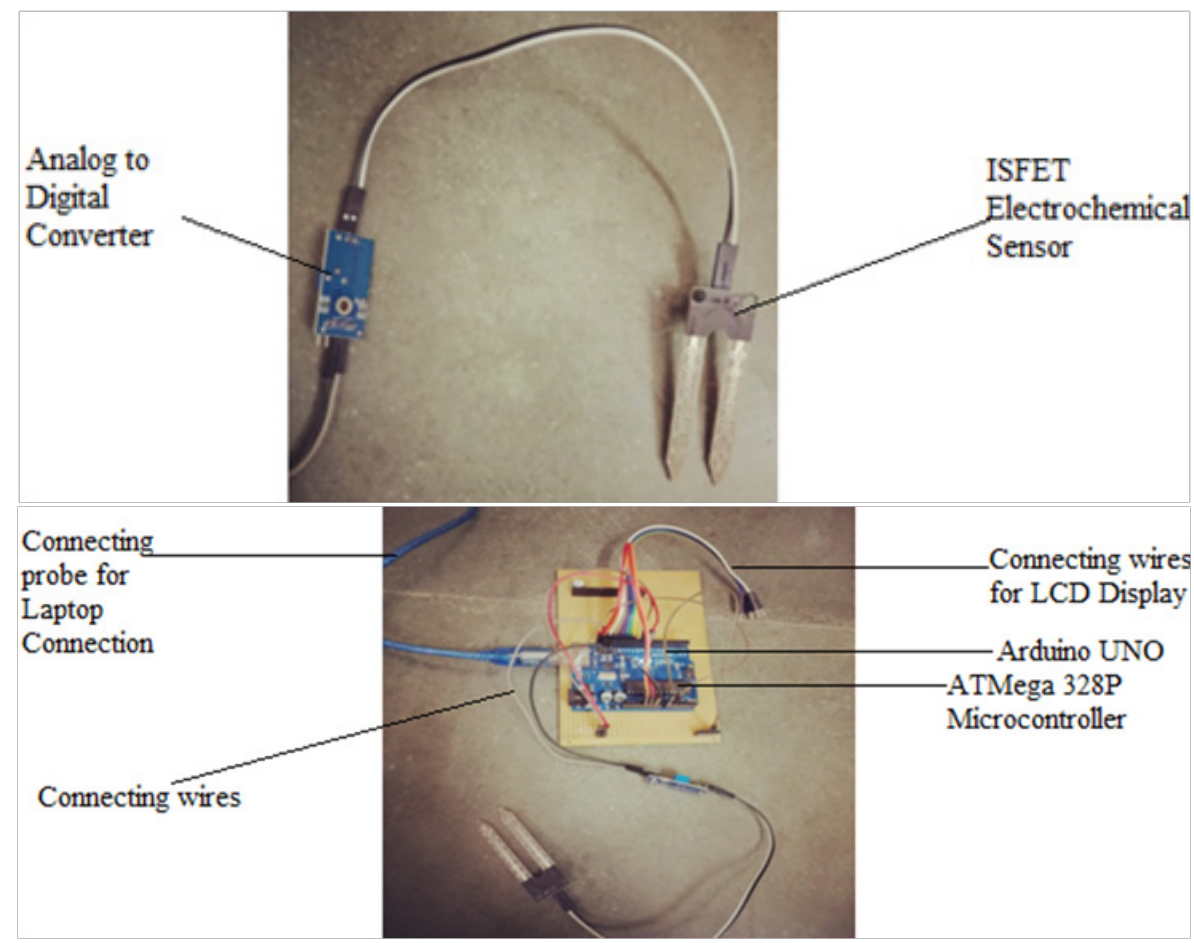

Figure 2 ISFET electrochemical sensor \& sensor circuit. 


\section{Ion selective FET}

It is assimilation of ISE and FET. By placing the ion selective membrane on the upper insulated layered of FET structure, by doing so ISFET threshold voltage gets modulated. The concentration of the targeted ion is interrelated with measured voltage. Advantages of ISFET include, higher signal to noise ratio, smaller construction, lower output impedance, response is faster than ISEs and the capability of multi-ISFETs to integrate on single chip. Other than NPK, more nutrients can be detected like $\mathrm{Co}, \mathrm{S}, \mathrm{Fe}, \mathrm{NH}_{4}$ etc.

\section{Arduino UNO}

These days it is very much required to build electronic devices and robust systems which senses and controls objects in this world. ${ }^{3}$ To fulfill this purpose arduino which is open source hardware has designed and manufactured microcontroller based kits. This system implements Atmega 32814 digital I/O pins along with 6 analog pins, $32 \mathrm{~KB}$ flash memory, serial communication interfaces, $1 \mathrm{~KB}$ EEPROM, $16 \mathrm{MHz}$ SRAM, $16 \mathrm{MHz}$ clock speed, power jack, $6 \mathrm{PWM}$ output pins, with the input voltage of $7-12 \mathrm{v}$ and operating voltage of $5 \mathrm{~V}$, USB connection for loading programs aiding languages like embedded $\mathrm{C}$, embedded $\mathrm{C}++$, Java. It supports an IDE for programming and coding the microcontroller which is based on processing. Arduino uno are the best documented board for the cool projects. ${ }^{4}$

\section{Soil sample}

Soil sample of the selected region where the crop (here, tomatoes) is grown is tested to know the NPK values.

\section{PC/Laptop}

The PC displays the value of soil moisture values along with the NPK values. The arduino code is also encoded with the language commonly known as embedded $\mathrm{C}$. The analog to digital converter is also provided.

\section{Azadirachta indica extract preparation}

The Azadirachta indica leaves from the trees were collected. It was made sure that the stems and midribs are excluded. Azadirachta indica leaves amount were weighted by using weighing machine. The leaves were washed by distilled water 2 to 3 times to remove dirt and foreign particles. The leaves were crushed and grinded in a mixer by adding small amount of distilled water to make a semi-solid paste. A cotton cloth was suspended over a big enough bucket to collect the extract. The mixture was placed on the cloth to filter the extract. The cloth was left with material suspended over the bucket or tub and latter was left to steep overnight in refrigerator. Aqueous filtrate was collected in the bucket and thus the strong and powerful Azadirachta indica extract was obtained. To filter the aqueous crude extract of Azadirachta indica, leaves were ones again added with more water to collect the residue in the cloth to filter out the remaining extract in the bucket. Or alternatively, we could just put the cloth inside a bucket or tub and steep it overnight. For the best use of the watery extracts, one can easily prepare the Azadirachta indica extract freshly as and when needed. The volume of leaves needed for the formation of extract is quiet high. Collected Azadirachta indica leaves from trees weighs 165 grams. Since 50grams of Azadirachta indica leaves are required for use in $1 \mathrm{~L}$ of extract. $330 \mathrm{~L}$ of extract was collected and measured in beaker to form a solution of $50 \mathrm{~g} / \mathrm{L}$. So the concentration of the aqueous solution of Azadirachta indica extract is $0.05 \mathrm{gram} /$ $\mathrm{mL}$. Boiling the extract is unnecessary as it reduces the azadirachtin content. Thus, cold extract is preferred. The filtrate is then stored in a can and refrigerated (Figure 3).

\section{Procedure}

A best location for gardening was selected. Crop was selected considering the prevailing weather conditions (here, tomatoes). 8 potholes were dug twice as deep and twice as wide as the pot size. In each holes 3 tomato plants were planted. The crops were water the plants regularly. Soil tests were performed at regular intervals by using electrochemical sensor. The soil moisture value and NPK values were noted. Tomato crops were provided with Azadirachta indica extracts at regular intervals. Do note down the concentration of aqueous solution of Azadirachta indica extract every time. All the plants were given different amount of concentration of solution at several time gaps to know all the physical changes in plant growth and keep record of NPK value of soil. Figure 4 shows the crop site when the tomato plants were initially planted (Figure 5 \& Figure 6) (Table 1).
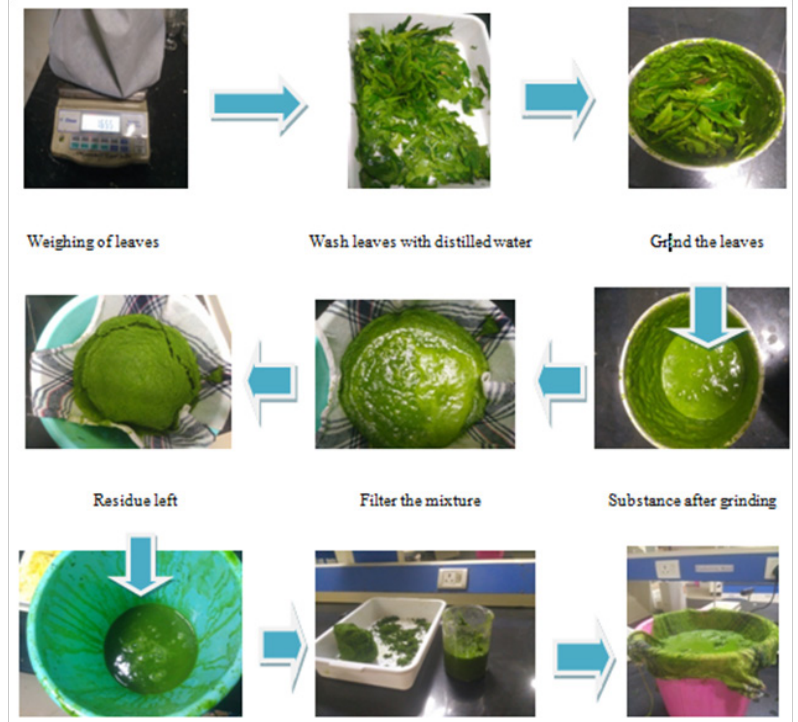

Aqueous solution
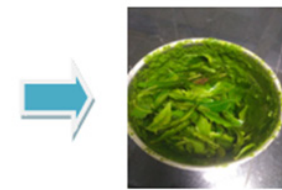

GInd the legves
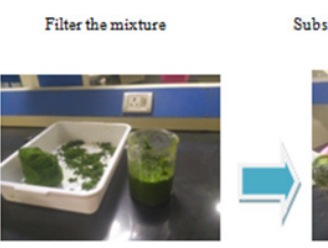

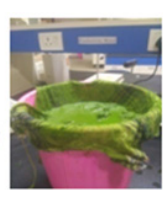

Re-filter the residue

Figure 3 Procedure for Azadirachta indica extracts preparation. 

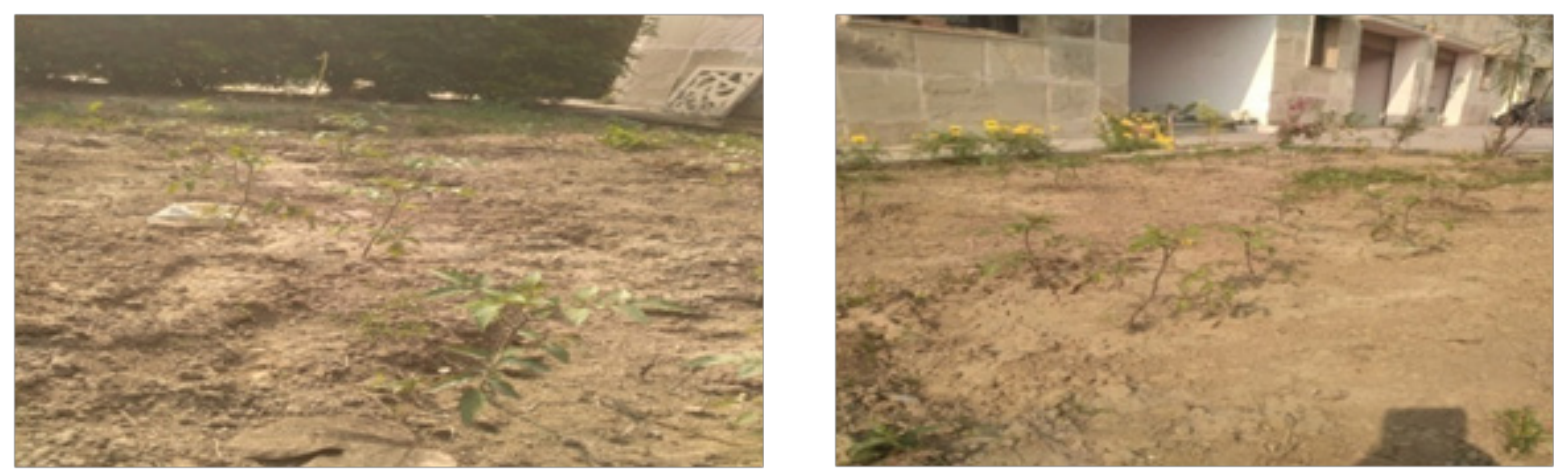

Figure 4 Crop site.
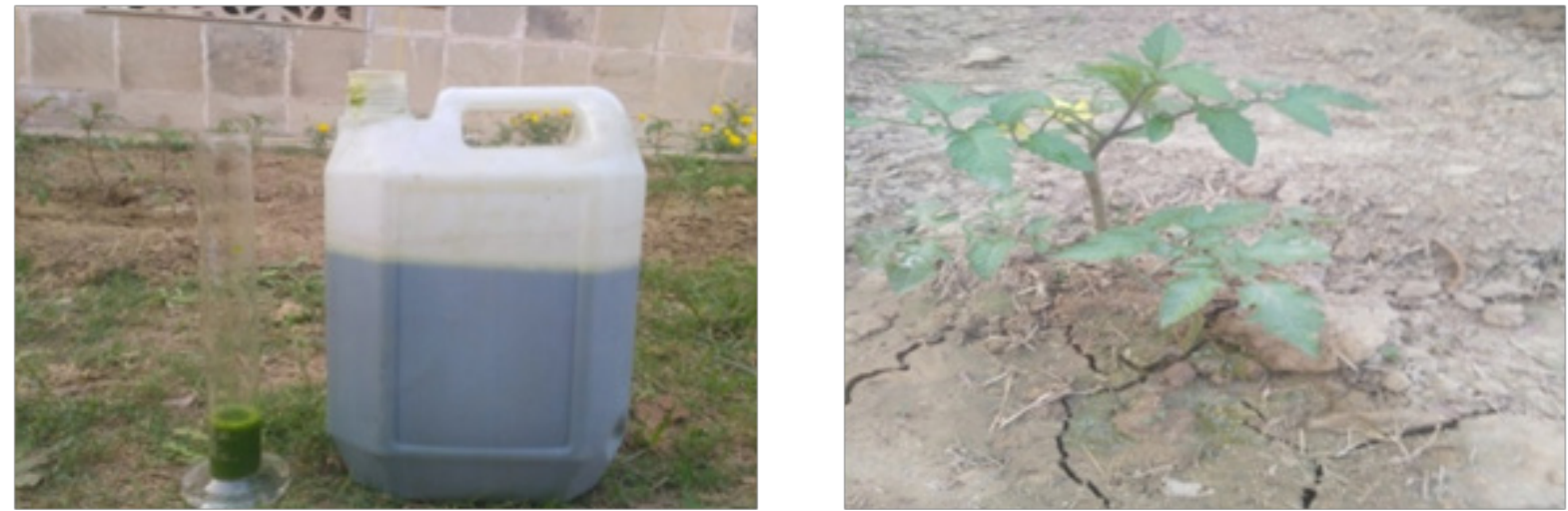

Figure 5 Crop site with Azadirachta indica extracts being measured and poured.

\section{COM4 (Arduino/Genuino Uno)}

Soil Moisture Value : 285

Nitrogen :

19.00

Phosphorus :

8.00

Potassium :

57.00

So11 Moisture Value : 285

Nitrogen :

19.00

Phosphorus :

8.00

Potassium :

57.00

Figure 6 Simulation results from Arduino from soil test l.

Citation: Chauhan N, Urooj S. The effect of Azadirachta Indica extract on the soil nutrients and the NPK value determination by electrochemical sensor. Int J Biosen Bioelectron. 2019;5(3):8I-87. DOI: 10.15406/ijbsbe.2019.05.00I58 
The effect of Azadirachta Indica extract on the soil nutrients and the NPK value determination by

Table I Soil test results

\begin{tabular}{|c|c|c|c|c|}
\hline Nutrient contents & $\begin{array}{l}\text { Soil test I values } \\
\text { (Initial) }\end{array}$ & $\begin{array}{l}\text { Soil test } 2 \text { values ( } 15 \\
\text { days later) }\end{array}$ & $\begin{array}{l}\text { Soil test } 3 \text { values ( } 30 \\
\text { days later) }\end{array}$ & $\begin{array}{l}\text { Soil test } 4 \text { values ( } 60 \\
\text { days later) }\end{array}$ \\
\hline $\begin{array}{l}\text { Moisture Content (this value depends upon } \\
\text { the water provided to crops before taking the } \\
\text { readings) }\end{array}$ & 285 & 287 & 287 & 286 \\
\hline Nitrogen & 19 & 20 & 22 & 24 \\
\hline Potassium & 57 & 57 & 59 & 59 \\
\hline
\end{tabular}

\section{Results}

\section{From the simulation results}

I. Nitrogen content is more readily increased up to $26 \%$.

II. Not much change in Phosphorous content is observed.

III. About 3.5\% change in Potassium content is observed.

\section{Physical parameters}

Figure 7 shows the plants in which the extracts were poured and the figure also represent the growth of plants for up to next 60 days. a) Plants treated with Azadirachta indica extracts displayed a fuller growth with spreading of about $40-45 \mathrm{~cm}$ (till date), leaves are more hairy, strongly odorous. The five-petaled flowers which are yellow $(2 \mathrm{~cm})$ across, pendant, and clustered. A number of tomato berries with green or yellow green colors are seen.

b) Untreated plant showed a lesser spreading, growth of flower but no fruit till date.

c) Also, as said before in this paper, the treated has more chlorophyll content (greener).

d) Figure 8 shows the plant growth for next 60days which was not provided with the extract.
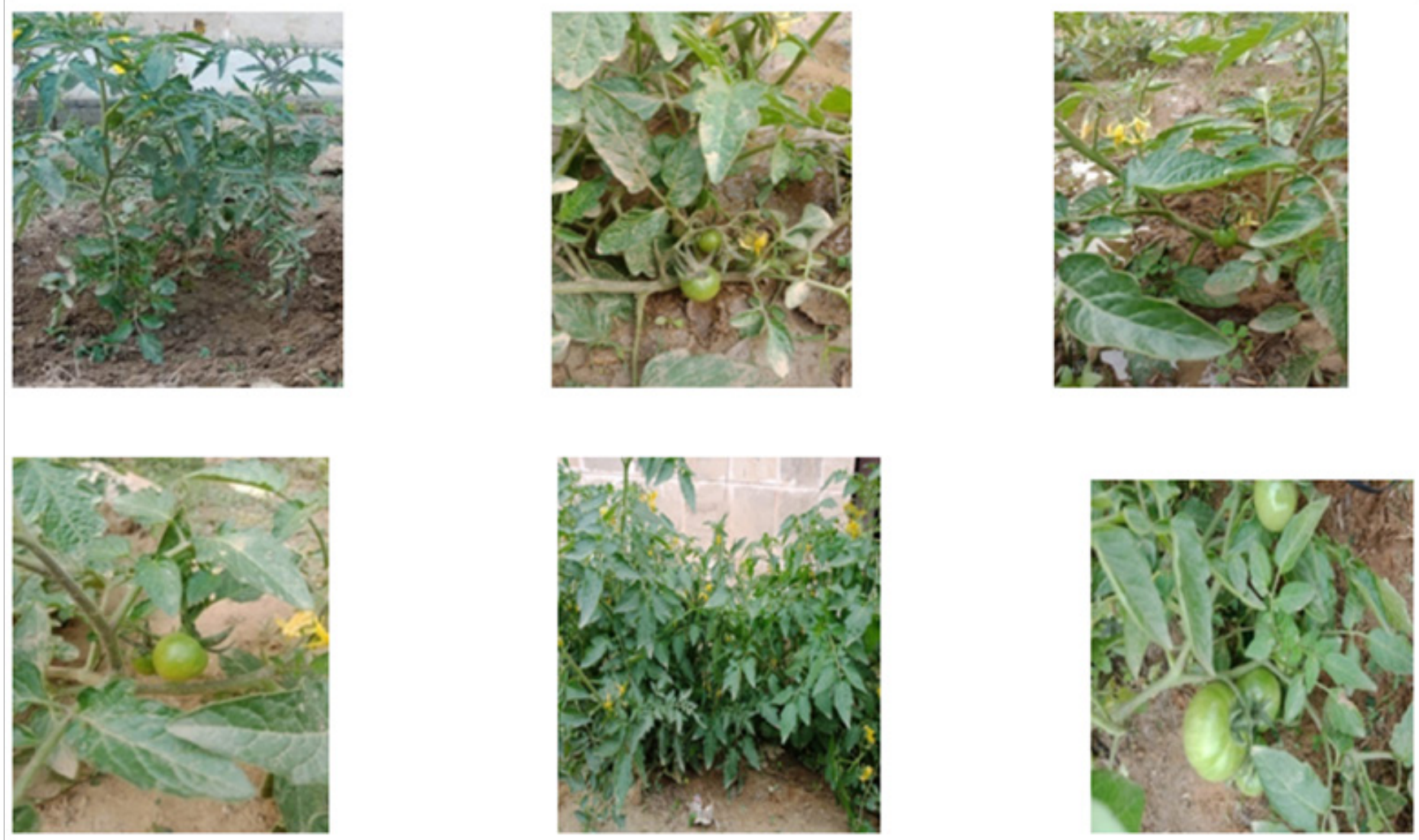

Figure 7 Treated tomato plants (with fruits). 


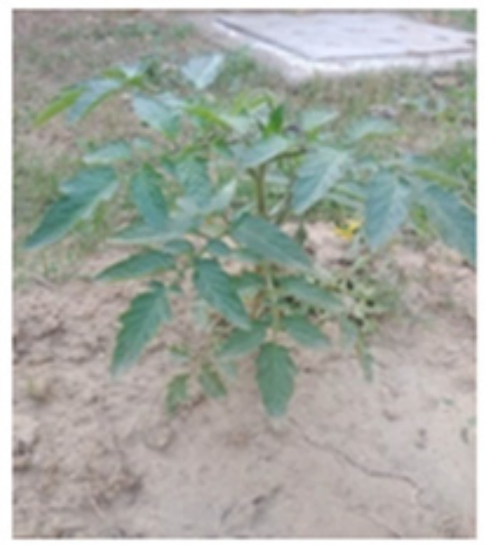

Figure 8 Untreated plants.

\section{Discussion}

The Azadirachta indica extracts being a biodegradable fertilizer because of its bioactivity shows changes in the NPK contents of the soil. This methodology further can be further extended by using neem cakes (extracts + urea) which can show results better effectively. Extract concentration in every pot hole is varied at different instant of time. To become $100 \%$ effective, the effect takes at least 6 weeks. The half life of azadirachtin in soil ranges from 3 to 44days. The extract used is a complete natural product and does not contain any solvents or other harmful components. The treated plants shows the fuller growth with more flowers and fruits whereas the untreated plants though shows the progress but not as effective as treated plants.

\section{Conclusion}

Growing concern about nutrient degradation in soil due to the excessive use of synthetic fertilizers has lead to time for the commitment of soil nutrients identification. Azadirachta indica extract being an organic substance improves the absorption and reduces nitrogen leaching. It increases the amount of nutrient in the soil and facilitates flora and fauna development. This sensor based technology will aid the farmers to take on the soil necessities that will help them with liable decision making and preventions at the right moments leading to rise in the soil fertility. Thus, saving farmers time, money and make effective use of resources. This method can be further extended to other extracts like Aloe Vera extracts and others. ${ }^{5-23}$

\section{Acknowledgments}

None.

\section{Conflicts of interest}

Author declares that there is no conflict of interest.

\section{References}

1. www.ijaiem.org

2. Salve Akshay, Sagar Sonali, Patne Mahesh, et al. Soil Nutrient Identification Using Arduino And Electrochemical Sensor. International Research Journal of Engineering and Technology. 2018;5(2).

3. https://store.arduino.cc/usa/arduino-uno-rev3

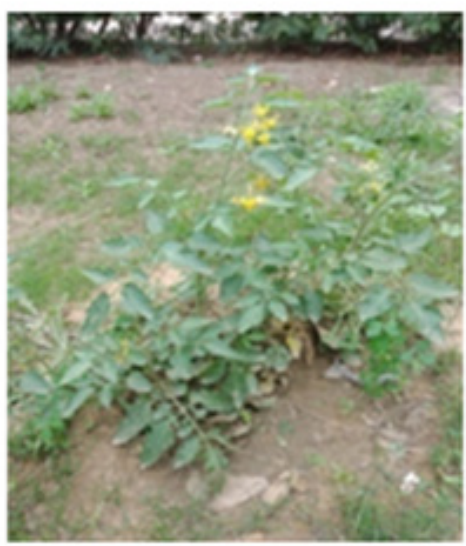

4. https://www.arduino

5. R.Sindhuja, B.Krithiga. Soil Nutrient Identification Using Arduino. Asian Journal of Applied Science and Technology. 2017;1(4):40-42.

6. Stablen ML, Ellsworth JW, Sullivan DM, et al. Monitoring Soil Nutrients Using Management Unit Approach. PNW 570-E. 2003.

7. Carrie AM Laboski, John B. Peters. Nutrient Application Guidelines for Field, Vegetable, Fruits and Crops in Wincosin" (A2809). 2013.

8. Hue NV, Uchida R, Ho. Sampling and Analysis of Plants and Soil Tissues, How to take representative samples, How the samples are tested. Plant Nutrient Management in Hawaii soils, Approaches for Tropical and Subtropical Agriculture. 2014.

9. Jones C, Jacobsen J. Plant Nutrition and Soil Fertility. Nutrient Management Modules. 2016

10. A Survey on Soil Testing. 2015.

11. Rossner J, Zebitz CPW. Effect of soil treatment with Azadirachta indica products on earthworms (Lumbricidae). Proceedings of the 3 International Azadirachta indica Conference, Nairobi. 1986:627-632.

12. Adesemoye AO, Ugi EO. Evaluating Pseudomonas aeruginosa as plant growth-promoting rhizobacteria in West Africa. Arch Phytopathol Plant Prot. 2009;2:188-200.

13. Zhang Miao, Wang Maohua, Chen Li, et al. An Automatic Fluidic System for the Rapid Detection of Soil Nutrients. Proceedings of the IEEE International Conference on Automation and Logistics. 2008:2742-2746.

14. Shibusawa S. On-line Real Time Soil Sensor. Proceedings of the 2003 IEEE/ASME International Conference on Advanced Intelligent Mechanics. 2003:1061-1066.

15. Adamchuk VI, Hummel JW, Morgan MT, et al. On-the-go Soil Sensors for Precision Agriculture. 2004.

16. Jayaprahas J Navin K, Sivachandran S, et al. Real Time Embedded Based Soil Analyzer. International Research Journal of Engineering and Technology. 2014;3(3).

17. Deepa V Ramane, Supriya S Patil, Shaligram AD. Detection of NPK nutrients of soil using Fiber Optic Sensor. Proc IJRAT. 2015: 13-14.

18. Ananthi C, Azha Periasamy, Manikandan N. Agriculture Land Maintains By Arduino. Proc 18th IJSRD. 2014:2321-0613.

19. Janata J. Thirty years of CHEMFETs - A personal view. Electroanalysis. 2004; 16:1831-1835 
20. Kim HJ, Hummel JW, Sudduth KA, et al. Simultaneous analysis of soil macronutrients using ion-selective electrodes. Soil Science Society of America Journal. 2007;1:1867-1877.

21. Tamal Adhikary, Amit Kumar Das, Md Abdur Razzaque, et al Test Implementation of a Sensor Device for Measuring Soil Macronutrients. International Conference on Networking Systems and Security(NSysS). 2015.

22. Nattapol Kaewmard, Saiyan Saiyod. Sensor Data Collection and Irrigation Control on Vegetable Crop Using Smart Phone and Wireless Sensor Networks for Smart Farm. IEEE Conference on Wireless sensors (ICWiSE). 2014:106-112.
23. https://www.google.com/search? q=electrochemical + sensors + for + soil + test\& $\operatorname{source}=1 \mathrm{nms} \& \mathrm{tbm}=\mathrm{isch} \& \mathrm{sa}=\mathrm{X} \& \mathrm{ved}=$ 0ahUKEwig347X17rgAhVJOisKHZ5JD1gQ_AUIDigB\&biw= 1366\&bih=624\#imgrc $=\mathrm{OaZsNrFde-eKM}$ 